\section{Formal controls and team adaptability in new product development projects}

Formal controls and team adaptability

\author{
Nina Detzen
}

Vrije Universiteit Amsterdam, Amsterdam, The Netherlands and Utrecht University, Utrecht, The Netherlands

Frank H.M. Verbeeten

University of Amsterdam Business School, Amsterdam, The Netherlands

Nils Gamm

Unaffiliated Researcher, and

Klaus Möller

University of St Gallen, St Gallen, Switzerland
Received 19 July 2017 Revised 20 December 2017 Accepted 28 January 2018

\begin{abstract}
Purpose - The purpose of this paper is to investigate the effects of two formal controls, namely target rigidity and process autonomy, on team adaptability and project success in new product development (NPD) projects. Target rigidity refers to performance goals that are non-negotiable once they have been set. Process autonomy refers to the extent to which a project team is free to choose ways to achieve its goals. Team adaptability is considered a key factor that explains the relationship between formal controls and project success.

Design/methodology/approach - Two separate models related to resource and cost measures are analysed, since different target types may influence managerial perceptions. This study uses data collected from a survey with 113 project managers as respondents.

Findings - The findings show that target rigidity and process autonomy support team adaptability. Furthermore, team adaptability mediates the impact of formal controls on project success. The effects are more pronounced for cost targets as compared to resource targets.

Practical implications - Firms can increase project success by using formal controls in such a way that they allow project managers to provide their teams with motivating guidelines (target rigidity) and discretion (process autonomy) to adapt to new circumstances.

Originality/value - This study reveals the impact of formal controls on NPD project success through team adaptability. A balanced use of target rigidity and process autonomy may help improving NPD project success. Keywords Formal controls, New product development projects, Performance measure use, Team adaptability Paper type Research paper
\end{abstract}

\section{Introduction}

Controlling new product development (NPD) projects is a fundamental concern for companies, executives and research and development managers (Chiesa and Masella, 1996; Bonner et al., 2002; Chiesa et al., 2009; Zhu and Chen, 2016), and the selection of the "right" formal controls is considered a crucial managerial task (Henttonen et al., 2016). Facing turbulent dynamics in competitive areas, shortened life cycles, globalisation, reduced time to

(C) Nina Detzen, Frank H.M. Verbeeten, Nils Gamm and Klaus Möller. Published by Emerald Publishing Limited. This article is published under the Creative Commons Attribution (CC BY 4.0) licence. Anyone may reproduce, distribute, translate and create derivative works of this article (for both commercial and non-commercial purposes), subject to full attribution to the original publication and authors. The full terms of this licence may be seen at http://creativecommons.org/licences/by/4.0/legalcode

The authors would like to thank participants of the 2015 Annual Congress of the European Accounting Association (Glasgow), the 2013 Annual Conference for Management Accounting - Doctorial Colloquium (WHU Otto Beisheim School of Management) and the 2012 research colloquium with John Burns (WHU Otto Beisheim School of Management) for their valuable feedback at different stages of the project. 
market, and increased NPD costs and risks (Chiesa et al., 2009), firms increasingly have to balance flexibility and control related to their performance measure use (Henri, 2006). Thus, one goal in controlling NPD projects is to avoid unpleasant surprises in order to assure that the NPD project is on track and delivers new products that meet customer needs (Bonner et al., 2002). Another goal is to ensure that formal controls do not interfere with the necessity that NPD teams are innovative and creative, and adapt quickly to new developments in the NPD project (Henri, 2006). Furthermore, previous literature has argued that adaptability affects firm performance (e.g. Thongpapanl et al., 2012) and that team adaptability is key for project success (e.g. Klarner et al., 2013), yet we have little empirical evidence on how formal controls affect team adaptability in NPD projects. Despite the emerging notion that formal controls will affect NPD success (e.g. Rijsdijk and Van den Ende, 2011; Chong and Mahama, 2014; Henttonen et al., 2016), it is insufficiently clear to which extent formal controls and team adaptability jointly affect NPD project success.

To address this gap, we investigate the relationship between formal controls, team adaptability and project success for two key performance measures in NPD projects: cost and resource allocation (Henttonen et al., 2016). Cost and resource allocation decisions are amongst the most important decisions in every NPD project, and firms usually provide specific targets in these areas (Davila, 2000; Thamhain, 2003). We focus on the use of two specific formal controls that are argued to help achieve a balance between predictable goal achievement and creative innovation: target rigidity (an output control) that provides direction for project execution and can be used to monitor progress, and process autonomy (a behaviour control) that provides autonomy to adapt project activities to new developments in the NPD project. We argue that these controls provide the motivation (output controls) and discretion (behaviour controls) for the team to adapt to new developments in the NPD project, which subsequently affects NPD project success. We empirically test our research model based upon data collected from a survey of 113 NPD project managers. We analyse the effectiveness of target rigidity and process autonomy for resource and cost measures in separate models as project managers may use these measures differently.

Our paper makes three contributions to the literature. First, formal controls have traditionally been regarded as devices that are used to monitor and evaluate performance (Henri, 2006), yet with the tendency to hamper innovation (Damanpour, 1991; Amabile, 1998). However, recent empirical literature suggests that formal controls may contribute to NPD project success (e.g. Davila, 2000; Salomo et al., 2007; Rijsdijk and Van den Ende, 2011). We extend previous research by providing empirical evidence on the positive role that formal controls may play when they are used to communicate targets as well as provide autonomy to NPD teams. Second, previous literature has documented the importance of adaptability for firm performance (Thongpapanl et al., 2012); in addition, some studies have investigated the importance of team adaptability for team performance in specific industries (such as the consulting industry; see, e.g. Klarner et al., 2013). In general, these studies also document the critical role of the organisation's structural context that affects the relationship between adaptability and performance (see also Chiesa et al., 2009). We extend previous research by documenting the mediating role of team adaptability in the relation between formal controls (one aspect of the organisation's structure) and project success in a NPD setting. Hence, this paper documents two antecedents (i.e. target rigidity and process autonomy) of team adaptability and NPD project success; in addition, it opens the "black box" on how specific formal controls affect NPD project success. Finally, previous research has provided evidence on the importance of different performance measures in NPD settings (Davila, 2000; Thamhain, 2003; Henttonen et al., 2016). We extend this research by investigating the role of formal controls relating to two important targets in most NPD projects: costs and resource allocation. Contrary to our expectations, we find little empirical evidence for the difference between specific performance measures. 
The remainder of this paper is structured as follows: in the second section, we introduce team adaptability and discuss the advantages and disadvantages of output and behaviour control in innovative settings as a foundation for our theoretical model and the development of our corresponding hypotheses. The third section provides an overview of the data collection and the survey measures, while we discuss the empirical results in the fourth section. Finally, we present out conclusions and recommendations for further research in the fifth section.

\section{Literature review and hypotheses development}

\section{Team adaptability and project success}

NPD project teams involve a project leader and the participation of members from several organisational functions (e.g. sourcing, development, production, finance and marketing). We define a team as a group of individuals who work interdependently and bear responsibility to achieve project and organisational outcomes (Sundstrom et al., 1990). NPD projects are characterised by high unpredictability due to changing (information on) internal and external requirements; this limits planning accuracy and increases the need for the team to adapt their activities to new developments in these projects (e.g. Dvir et al., 2006). Literature defines team adaptability as modifications of actions and processes by the team to respond to changed requirements (LePine, 2003; Burke et al., 2006; Klarner et al., 2013). Team adaptability is vital to minimise the consequences of inevitable changes (Dvir and Lechler, 2004) and to effectively achieve goals in NPD projects (Tatikonda and Montoya-Weiss, 2001; Sethi and Iqbal, 2008). If a project team succeeds in using information gathered from the project environment to identify emerging changes and to implement adjustments to team processes with little effort early on, it is more likely that the team will increase project success (Thamhain, 2003; Burke et al., 2006; Klarner et al., 2013). However, NPD project success is a multi-faceted concept (Sicotte and Bourgault, 2008). In this study, we define project success as the extent to which operational goals (time, cost) and financial goals (profitability) are achieved. Costs and time are critical indicators for NPD projects (e.g. Atkinson, 1999; Tatikonda and Montoya-Weiss, 2001); profit goals relate to the overall NPD project performance (Cordero, 1990).

Our preceding argumentation implies that teams' changes to NPD project processes contribute to project success. However, not every (well-intentioned) adjustment during project execution is necessarily for the better. Imbalances in power among project leader and team members (that provide the opportunity to prioritise a project leader's pet project) or inadequately distributed decision rights (that do not match information requirements) may result in detrimental process changes. Nonetheless, we assume that team adaptability is - in general - in favour of NPD project success:

H1. Team adaptability positively influences project success.

\section{Formal controls and team adaptability}

Formal control use in NPD projects. Traditionally, controls have been considered as means to monitor and evaluate behaviour or outputs (Davila, 2005). The restrictive nature and related (alleged) negative effects of formal controls on innovative activities have long been the primary concern (Amabile, 1998). However, more recent studies show that the effect of controls depends on the specific form of control that is applied, and the way in which it is used in innovative settings (Tatikonda and Rosenthal, 2000; Bonner et al., 2002; Jørgensen and Messner, 2009; Rijsdijk and Van den Ende, 2011; Bedford, 2015).

As it is close to impossible to avoid formal controls - even in innovative settings - it is important to investigate ways in which their use is most effective (Cardinal, 2001). We focus our analysis on the traditional differentiation between output and behaviour controls (e.g. Snell, 1992), yet adopt the more recent understanding of controls that allows delegating responsibilities and empowering NPD team members in benefit of team adaptability and 
project success (e.g. MacBryde and Mendibil, 2003). This perspective emphasises formal controls' different purposes which are not focussed solely on monitoring and constraining actions but also include directing and learning (Simons, 1990).

Effective use of controls in NPD projects requires that the formal controls fulfil at least two preconditions. First, the teams need performance targets (output controls) in order to ensure that changes to the team activities are goal-directed improvements (Marks et al., 2001; LePine, 2003). Second, NPD teams need a certain amount of autonomy (behaviour control) to benefit from the different members' knowledge and expertise and implement process improvements to achieve project goals (Bonner et al., 2002).

Target rigidity's effect on team adaptability. Output-oriented controls are beneficial in innovative settings because they give direction without regulating processes (Cardinal, 2001; Bonner et al., 2002; Rijsdijk and Van den Ende, 2011). In this study, we focus on a specific output control: target rigidity. It is defined as the extent to which performance targets are non-negotiable once they have been determined and thus remain stable during a project (Sethi and Iqbal, 2008). Performance targets provide team members the autonomy to choose actions to achieve specified performance targets (i.e. to decentralise decision making; Snell, 1992). Employees, in turn, have to respond quickly, if unforeseen changes require adaptions to project processes to achieve the pre-specified performance target, which allows for novel approaches and creative problem solving (Turner and Makhija, 2006).

Second, specified targets help to identify disadvantageous variances. Especially when procedures are new and untried, rigid targets provide points of reference to recognise potential deviations from targets early on. Furthermore, specific rigid performance targets are considered to encourage team members to aim at higher performances (LePine, 2005). Finally, clarity on joint targets can help NPD teams to focus on a shared vision and coordinate their tasks accordingly (Hu and Liden, 2011). The NPD project success depends on teams' ability to coordinate tasks and take corrective actions in case unfavourable developments occur (Mundy, 2010; Bedford, 2015).

However, a strong reliance on output controls may also involve risks for NPD projects. It may cause employees to focus too much on attaining given targets and increase risk-aversion, and discard opportunities (Snell, 1992). As a result, employees may favour work on incremental innovations as their outcomes are easier to predict and achieve (Cardinal, 2001). In addition, employees may engage in unethical behaviour (e.g. creation of slack, manipulation of targets and/or project performance measures) in order to achieve the specified targets (Van der Stede, 2000; Den Nieuwenboer et al., 2017). Empirical evidence on the effect of output controls is mixed: some studies indicate that output controls positively affect NPD performance (Salomo et al., 2007; Rijsdijk and Van den Ende, 2011; Bedford, 2015), while others find no support for this relationship (Bonner et al., 2002). Differences in innovativeness level seem to have no effect on this relationship (Cardinal, 2001; Bonner et al., 2002; Salomo et al., 2007; Henttonen et al., 2016).

Based upon the previous review, we argue that rigid targets guide NPD teams' actions, help identify unfavourable deviations from pre-set targets, and enhance team effort and collaboration towards the pre-set targets; these aspects will support NPD teams to adapt to changes in a timely manner:

H2a. Target rigidity related to performance targets positively influences team adaptability in NPD projects.

Process autonomy's effect on team adaptability. Behaviour controls can be defined as the regulations and procedures that prescribe the actions that team members should take to achieve the goals of the organisation (e.g. Davila, 2005; Rijsdijk and Van den Ende, 2011). Recent studies indicate that behaviour controls inhibit adaptions in NPD projects and negatively affect project performance (Bonner et al., 2002; Rijsdijk and Van den Ende, 2011). 
To avoid these negative outcomes, Bonner et al. (2002, p. 241) suggest that teams "should determine their own process and procedural controls"; in other words, teams should have some degree of process autonomy.

For the purposes of this paper, we define process autonomy as the extent to which a project team is free to choose ways and means to achieve performance targets, to organise the extent of certain activities and to determine a convenient time to conduct them (Schrader and Göpfert, 1998). Process autonomy may be regarded as the "inverse" of behaviour control; it provides the NPD team the chance to modify actions and processes when necessary, which are vital aspects of team adaptability (Klarner et al., 2013). Restricting NPD teams' process autonomy may have detrimental effects on the outcome of innovative projects as it may reduce problem solving capability of NPD teams and project efficiency (Rijsdijk and Van den Ende, 2011).

Based upon the previous review and in line with Burke et al. (2006, p. 1198), we argue that teams with a high level of process autonomy (i.e. few behaviour controls on processes) "will be more likely to successfully formulate and carry out effective plans and thereby ultimately be more adaptive". Formally, we state:

$H 2 b$. Process autonomy when pursuing performance targets positively influences team adaptability in NPD projects.

\section{Differences between types of targets}

In NPD projects, project managers are confronted with a magnitude of project demands and associated information. Depending on the project's strategic focus and type of innovation, different information may be relevant (Henttonen et al., 2016; Davila, 2000). When a project has a high cost orientation due to the firm's competitive strategy or the market environment, detailed cost information is valuable to project managers. Information on resource allocation, on the other hand, helps to plan and monitor the effectiveness of the NPD process (Henttonen et al., 2016). Relative to cost-oriented performance measures, resource measures are less likely to restrict team members' actions during project execution, but strengthen the focus on adequate resource allocation throughout the project (Davila, 2000).

Psychological factors may also influence project managers' perceptions and interpretations of the relevance of information (Cooper, 2003). Individuals perceive situations via cognitive systems, through which they evaluate and make sense of the situations they are in and which leads them to pursue or avoid actions (Chang et al., 2008). Using performance measures allows project managers to control perceived risks. Managers generally tend to avoid, reduce or control risk, rather than accept it (March and Shapira, 1987). In addition (project) managers seem to perceive cost overruns as critical: "Risk has become increasingly a term referring not to the unpredictability of outcomes, but to their costs" (March and Shapira, 1987, p. 1411). This awareness of costs is likely to result in a different attention to cost measures relative to resource measures in project goal achievement:

H3. The extent to which target rigidity and process autonomy affect team adaptability and NPD project success differs with the type of measure (i.e. resource and cost measure).

Our conceptual model is reflected in Figure 1. As noted earlier, we expect that formal controls (target rigidity and process autonomy) affect team adaptability ( $H 2 a$ and $H 2 b$ ), which fosters project success (H1). Thus, our conceptual model implies a mediating effect of team adaptability in the relationship between formal controls and project success. We explicitly test for this indirect relation. Furthermore, we test the hypotheses for resource and cost measures in two separate models to draw conclusion regarding their distinct use (H3). 
$\mathrm{MD}$

56,7

1546

\section{Research methods}

\section{Sample and data collection}

To test our hypotheses, we use a survey to obtain data from project managers. Project managers are actively involved in NPD teams and thus have critical knowledge of operational activities (Hirst and Mann, 2004; Blindenbach-Driessen et al., 2010) and bear responsibility for teams' adherence to performance targets during a project. Project managers are therefore aware of the extent to which targets are rigid, and they can assess the extent to which project teams are allowed to influence projects' processes. We chose to limit our survey to projects that involve the development of physical products for the industrial goods sector to ensure comparable survey answers. Furthermore, the respective projects had to be finished in order to evaluate project success.

We focus on two distinct industries in Germany: Aerospace and Electronics. Two industry associations (German Aerospace Association, BDLI; and German Electrical and Electronic Manufacturer's Association, ZVEI) supported the research project. The survey focusses on medium or large companies (i.e. with more than 50 employees or that achieve more than $€ 10$ million in annual sales) as companies generally require a certain size to use performance measures in NPD projects.

Each company was asked to name approximately ten project managers of successful and less successful projects as contact persons. If these project managers wished to participate, we sent them the questionnaire. To enhance the response rate, several incentives were offered (e.g. an individual benchmark and a report of the scientific results). Project managers who did not respond received e-mail reminders (after four and seven weeks). Overall, 133 project managers participated in the survey, representing a 70 per cent response rate. The database comprised 79 project managers from 16 companies in the electrical engineering industry and 51 from 13 aerospace industry companies. Three additional questionnaires were returned anonymously. Nine questionnaires had to be eliminated from the sample due to the fact that the respondents were not project managers. Of the respondents, 11 did not use any performance measures at all in the project; the remaining respondents (113) use at least one performance measure type (i.e. resource or cost measures), while some use both types. We separately tested the hypotheses for the different performance measures, namely resource $(n=87)$ and cost targets $(n=86)$.

\section{Measures}

We test our theoretical assumptions based on four latent constructs and three control variables (see Appendix 1). We use reflective measurement assuming a causal relationship between the construct and its indicators (Jarvis et al., 2003).

Target rigidity is measured using an adaptation of a measurement instrument from Sethi and Iqbal (2008). The indicators focus on the extent to which targets were rigid, and had to be adhered to once they had been determined. The participants were asked to estimate target rigidity individually for resource and cost targets.

Figure 1.

Theoretical model

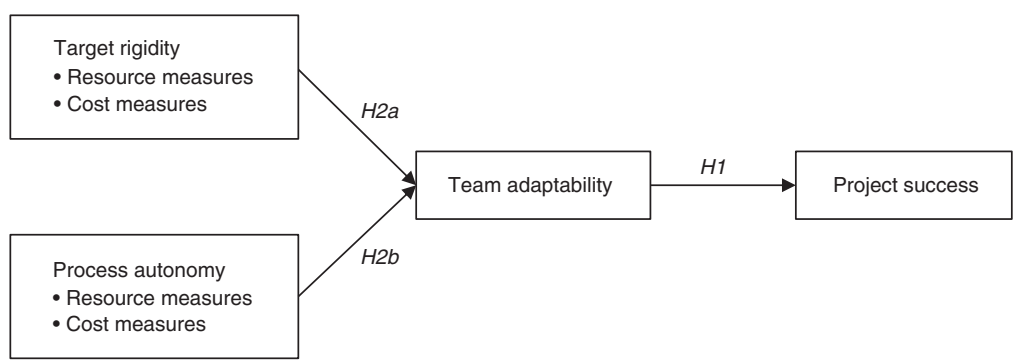


Based upon literature (e.g. Bonner et al., 2002), we use a purposely developed set of three indicators to measure process autonomy. Project managers were asked to evaluate the extent to which their project teams are free to determine ways and means, a convenient time, and the extents of certain activities in order to achieve the project targets. Participants were again asked to indicate process autonomy individually concerning resource and cost targets.

Regarding team adaptability, we focus on the teams' ability to adapt to unpredictable work situations (Pulakos et al., 2000). Project managers were asked to estimate the extent to which they and their project teams were able to identify changes and to react accordingly (Pulakos et al., 2000; Klarner et al., 2013).

Project success reflects process-related as well as outcome-related aspects of product development project success (Brown and Eisenhardt, 1995). We use five indicators, of which two relate to the launched product's market success (i.e. profit goals) and three to the project execution (i.e. adherence to time and cost goals).

Furthermore, we collect data on several control variables. First, project managers were asked to estimate the extent to which several internal and external factors were unpredictable (e.g. Sicotte and Bourgault, 2008); we use unpredictability in a robustness check of our theoretical model. We include project managers' tenure as a control variable as tenure may be associated with leadership skills and with the capability to delegate and effectively lead a team (e.g. Rauniar et al., 2008). Finally, we include project size, measured as the number of full-time workers involved in a project (see Table I), and industry (electronic engineering vs aerospace) as control variables (e.g. Thongpapanl et al., 2012). We analysed the effects of all control variables on all latent constructs.

\section{Results}

We use a variance-based partial least square (PLS) approach to confirm empirical validation of the hypothesised effects (Hair et al., 2011, 2014). PLS approaches are employed to make statements about assumed relationships and to contribute to theory development (Henseler et al., 2009; Esposito Vinzi et al., 2010). We use SmartPLS 2.0 (M3) to evaluate the structural model (Ringle et al., 2005).

\section{Measurement model}

In a first step, we evaluate the measurement model (i.e. the fit between constructs and indicators). The values of the factor loadings should exceed 0.7 (Götz et al., 2010), while loadings below 0.4 should be excluded (Hulland, 1999) to ensure the indicators' reliability. Only a few indicators are just below 0.7, but well above 0.4 (see Table II). Regarding the composite reliability and Cronbach's $\alpha$, values of above 0.7 indicate a construct's internal consistency (Ringle et al., 2006; Hair et al., 2011). The results indicate that each construct's composite reliability is above 0.8 , while Cronbach's $\alpha$ are a little lower, although all still above 0.7 (see Table III).

To ensure the convergent validity of the indicators, the average variance extracted (AVE) should reach a value of at least 0.5, to indicate that the greater part of the indicators' variance is explained (Götz et al., 2010; Hair et al., 2011). In addition, to verify the

\begin{tabular}{lrrr} 
& Mean & (Range) \\
\hline Project leader tenure & & & \\
Years in the company & 14 & $(1-31)$ & \\
Year in the position & 8 & $(1-25)$ & Table I. \\
Project size in FTE & 16 & $(0.6-120)$ & Sample specifications \\
Note: FTE, full-time equivalents & & & \\
\hline
\end{tabular}


$\mathrm{MD}$

56,7

1548

Latent variable

Item

Actual range Mean SD

(1)

(2)

(3)

(4) $t$-statistics

Model 1: resource measures $(n=87)$

(1) Target rigidity TargRig1

TargRig2

TargRig3

(2) Process autonomy ProcAut1

ProcAut2

ProcAut3

(3) Team adaptability

Adapt1

Adapt2

Adapt3

Adapt4

(4) Project success

Adapt5

ProjSuc1

ProjSuc2

ProjSuc3

ProjSuc4

ProjSuc5

$1-5$

$1-5$

$1-5$

$1-5$

$1-5$

$1-5$

$1-5$

$1-5$

$1-5$

$1-5$

$1-5$

$1-7$

$1-7$

$1-7$

$1-7$

$1-7$

$2.91 \quad 1.13$

$3.34 \quad 1.05$

$\begin{array}{ll}3.08 & 1.22\end{array}$

$2.90 \quad 1.16$

$\begin{array}{ll}2.66 & 0.93\end{array}$

$\begin{array}{ll}2.87 & 1.08\end{array}$

$\begin{array}{ll}3.52 & 0.94\end{array}$

$\begin{array}{ll}3.24 & 1.06\end{array}$

$\begin{array}{ll}3.05 & 1.07\end{array}$

$\begin{array}{ll}3.10 & 1.02\end{array}$

$\begin{array}{ll}3.22 & 0.98\end{array}$

$\begin{array}{ll}4.56 & 1.47\end{array}$

$3.86 \quad 1.59$

$3.96 \quad 1.41$

$\begin{array}{ll}3.29 & 1.52\end{array}$

$4.06 \quad 1.38$

$\begin{array}{lll}0.74 & -0.11 & 0.11\end{array}$

$\begin{array}{lll}0.89 & 0.15 & 0.20\end{array}$

$\begin{array}{lll}0.79 & 0.06 & 0.12\end{array}$

$\begin{array}{llll}0.07 & 0.68 & 0.07 & -0.03\end{array}$

$\begin{array}{llll}0.09 & 0.83 & 0.14 & 0.16\end{array}$

$\begin{array}{llll}0.05 & 0.91 & 0.21 & 0.04\end{array}$

$\begin{array}{llll}0.16 & 0.13 & 0.66 & 0.36\end{array}$

$\begin{array}{llll}0.14 & 0.09 & 0.76 & 0.28\end{array}$

$\begin{array}{llll}0.05 & 0.07 & 0.69 & 0.21\end{array}$

$\begin{array}{llll}0.09 & 0.12 & 0.76 & 0.34\end{array}$

$\begin{array}{lllll}0.22 & 0.23 & 0.84 & 0.44\end{array}$

$\begin{array}{llll}0.15 & 0.02 & 0.34 & 0.75\end{array}$

$\begin{array}{llll}0.20 & -0.01 & 0.46 & 0.76\end{array}$

$\begin{array}{llll}0.16 & 0.14 & 0.33 & 0.71\end{array}$

$\begin{array}{llll}0.16 & 0.14 & 0.33 & 0.71 \\ 0.35 & 0.10 & 0.25 & 0.76\end{array}$

0.19

0.05

Model 2: cost measures $(n=86)$

TargRig2

TargRig3

(2) Process autonomy ProcAut1

ProcAut2

ProcAut3

(3) Team adaptability

Adapt1

Adapt2

Adapt3

Adapt4

Adapt5

(4) Project success

ProjSuc1

ProjSuc2

ProjSuc3

ProjSuc4

Projsuc5

1-5

$1-5$

1-5

$1-5$

$1-5$

$1-5$

1-5

$1-5$

1-5

1-5

$1-5$

$1-7$

$1-7$

$1-7$

$1-7$

$1-7$

$\begin{array}{lll}3.49 & 1.07 & 0.85\end{array}$

$\begin{array}{lll}3.58 & 1.11 & 0.82\end{array}$

$\begin{array}{lll}3.49 & 1.22 & 0.84\end{array}$

$\begin{array}{lll}3.05 & 1.18 & -0.04\end{array}$

$\begin{array}{lll}2.62 & 1.02 & 0.07\end{array}$

$\begin{array}{lll}2.64 & 1.10 & 0.13\end{array}$

$\begin{array}{lll}3.57 & 0.93 & 0.28\end{array}$

$\begin{array}{lll}3.27 & 1.06 & 0.18\end{array}$

$3.07 \quad 1.04$

$\begin{array}{ll}3.09 & 0.99\end{array}$

$\begin{array}{ll}3.22 & 0.96\end{array}$

$\begin{array}{ll}4.48 & 1.47\end{array}$

$3.89 \quad 1.58$

$3.99 \quad 1.43$

$4.30 \quad 1.52$

$\begin{array}{ll}4.07 & 1.39\end{array}$

0.18

0.17

0.29

0.08

0.27

0.20
0.38

0.26

Note: SD, standard deviation

\begin{tabular}{|c|c|c|c|c|c|c|c|}
\hline \multirow[b]{2}{*}{ Latent construct } & \multirow[b]{2}{*}{ Composite reliability } & \multirow[b]{2}{*}{ Cronbach's $\alpha$} & \multirow[b]{2}{*}{ AVE } & \multicolumn{4}{|c|}{ Correlations and SQRT of AVE } \\
\hline & & & & (1) & (2) & (3) & (4) \\
\hline \multicolumn{8}{|c|}{ Model 1: resource measures $(n=87)$} \\
\hline (1) Target rigidity & 0.85 & 0.75 & 0.65 & 0.81 & & & \\
\hline (2) Process autonomy & 0.85 & 0.74 & 0.66 & 0.08 & 0.81 & & \\
\hline (3) Team adaptability & 0.86 & 0.80 & 0.55 & 0.19 & 0.19 & 0.89 & \\
\hline (4) Project success & 0.87 & 0.81 & 0.57 & 0.28 & 0.07 & 0.46 & 0.90 \\
\hline \multicolumn{8}{|c|}{ Model 2: cost measures $(n=86)$} \\
\hline (1) Target rigidity & 0.88 & 0.79 & 0.70 & 0.84 & & & \\
\hline (2) Process autonomy & 0.86 & 0.77 & 0.67 & 0.09 & 0.82 & & \\
\hline (3) Team adaptability & 0.86 & 0.79 & 0.54 & 0.30 & 0.16 & 0.55 & \\
\hline (4) Project success & 0.88 & 0.83 & 0.59 & 0.32 & 0.07 & 0.50 & 0.77 \\
\hline \multicolumn{8}{|c|}{ Notes: SQRT, square root; AVE, average variance extracted } \\
\hline
\end{tabular}

Table III.

Composite reliability, Cronbach's $\alpha$, and average variance extracted (AVE), discriminant validity and correlations

Notes: SQRT, square root; AVE, average variance extracted 
discriminant validity, the square root of the AVE (values in italic) should be higher than the correlation between the different constructs (Chin, 2010). As shown in Table III, the convergent as well as the discriminant validity adhere to the abovementioned criteria. In addition, the cross-loadings (see Table II in italics) confirm accurate assignment of the different indicators, since their correlations with the respective constructs are higher than with any other construct (Henseler et al., 2009; Chin, 2010). Table III indicates that target rigidity is associated with team adaptability and project success, and team adaptability is correlated with project success; however, process autonomy is not associated with project success. Somewhat surprising is the finding that target rigidity and process autonomy is not related; this suggests that firms make these decisions relatively independently.

\section{Structural model}

Table IV shows the results of the structural models (i.e. hypothesised relationships). In addition to the hypothesised paths, we control for the direct effects of formal controls on NPD project success. For each model, we used the recommended number of 5,000 bootstrap samples to test for the coefficients' significance using a two-tailed test (Hair et al., 2014). Figures 2 and 3 illustrate the structural models of resource and cost measures; the effects are more pronounced in the cost measures model.

The results show strong support for the positive association of team adaptability and NPD project success $(p<0.01)$ for both resource and cost measures; thus, $H 1$ is strongly supported.

\begin{tabular}{|c|c|c|c|c|}
\hline Path from & $H$ & $\begin{array}{l}\text { Path to } \\
\text { Team adaptability }\end{array}$ & $H$ & Project success \\
\hline
\end{tabular}

Model 1: resource measures $(n=87)$

$\begin{array}{ll}\text { Target rigidity } & H 2 a \\ \text { Process autonomy } & H 2 b\end{array}$

$0.19(1.63)$

$0.24(2.10)^{* * *}$

Team adaptability

$R^{2}$

Model 2: cost measures $(n=86)$

Target rigidity H2a

Process autonomy $\quad H 2 b$

Team adaptability

$R^{2}$

Notes: $H$, hypothesis; NP, not predicted. ${ }^{*} p<0.10 ;{ }^{*} p<0.05 ; * * * p<0.01$ (two-tailed)
0.17

$0.25(2.16)^{* *}$
$0.24(2.02)^{* *}$

0.19

$\mathrm{NP}$
$\mathrm{NP}$
$H 1$

H1

NP

NP

H1

1

Formal

controls and

team

adaptability

1549

$$
\begin{gathered}
0.19(1.73)^{*} \\
-0.05(0.40) \\
0.46(4.62)^{* * *} \\
0.26
\end{gathered}
$$

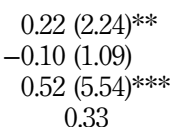

Table IV. Structural model: path coefficients ( $t$-statistics), $R^{2}$

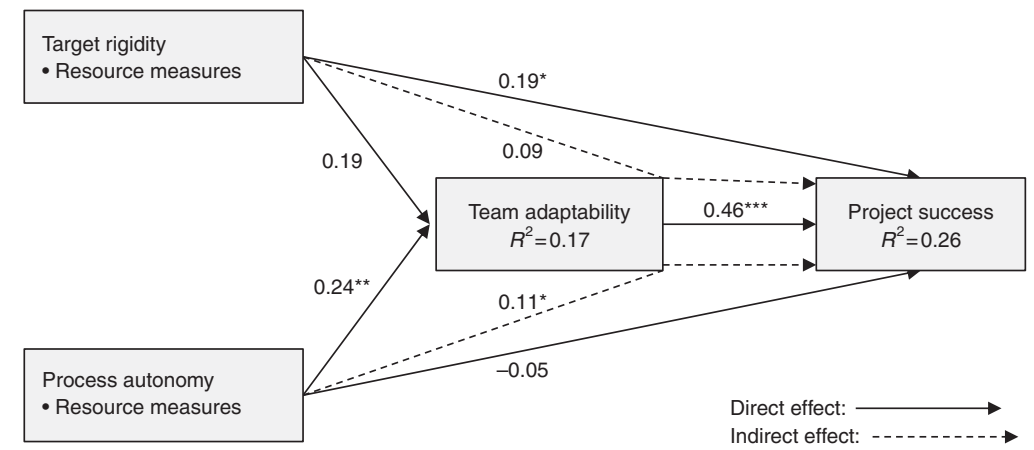

Figure 2.

Structural model 1: resource measures

Notes: ${ }^{*} p<0.10 ;{ }^{* *} p<0.05 ; * * * p<0.01$ (two-tailed) 
$\mathrm{MD}$

56,7

\section{0}

Figure 3.

Structural model 2: cost measures
Table V.

Mediating effect: effects ( $t$-statistics)

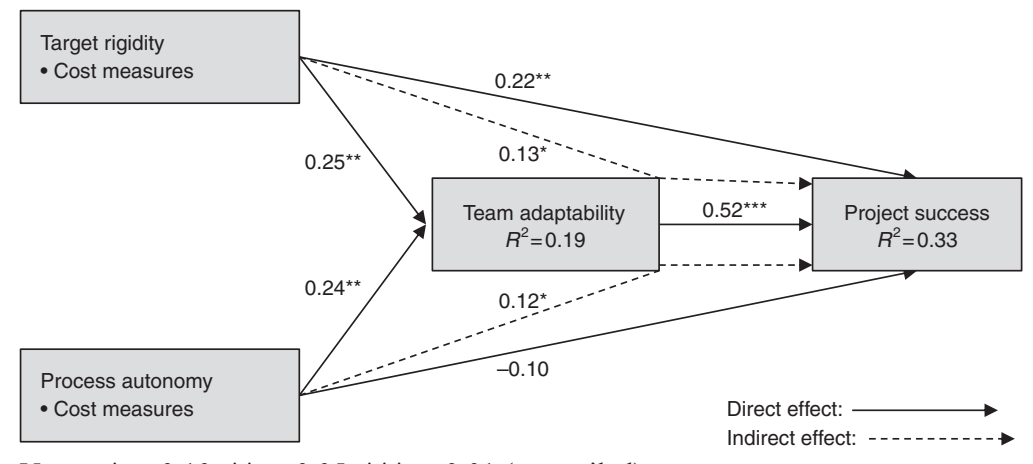

Notes: ${ }^{*} p<0.10 ; * * p<0.05 ; * * * p<0.01$ (two-tailed)

Consistent with $H 2 a$, target rigidity has a positive and significant influence on team adaptability; this holds for the cost measures $(p<0.05)$, however not for resource measures. Thus, $H 2 a$ finds only support for cost measures. The assumed effect between process autonomy and team adaptability is confirmed by the results $(p<0.05)$ for both models, which supports $H 2 b$.

We test the extent to which team adaptability explains the effects between target rigidity and process autonomy on project success (i.e. mediating effect) to get a better understanding of the relevance of team adaptability in NPD projects. Following Preacher and Hayes (2004), we test the indirect effects' significance using the bootstrapping procedure (with 5,000 samples). The results (see Table $\mathrm{V}$ ) show that team adaptability mediates the relationship between target rigidity and project success for cost measures $(p<0.1)$ (Model 2$)$ but not for resource measures (Model 1). Furthermore, we find evidence that team adaptability mediates the relationship between process autonomy and project success for both resource and cost measures $(p<0.1)$.

We also hypothesise a significant difference between the two models for resource and cost measures in H3. We conduct a parametric test[1] in order to analyse the models' path coefficients for significant differences. We followed the approach of multi group analysis as suggested by Hair et al. (2014)[2]. The results for the $t$-test show no significant differences between the paths of the resource and cost model; therefore, we cannot confirm H3 (see Table VI).

Finally, we turn to the effects of the control variables (tenure, size and industry; nontabulated). Project managers' tenure has a negative and significant effect on target rigidity regarding cost measures $(p<0.01)$. Industry affects process autonomy and team adaptability significantly in both models. Firms in the Electronics industry tend to provide more process autonomy to NPD teams (resource measure: $p<0.1$; cost measure: $p<0.01$ ), yet team adaptability in this industry is lower for cost measures $(p<0.05)$; furthermore, project success with regard to cost measures $(p<0.1)$ is perceived as higher in the Electronics industry. This suggests that the electronic engineering and aerospace industries handle NPD differently.

\begin{tabular}{|c|c|c|c|c|}
\hline Independent variable & Mediator & Dependent variable & $\begin{array}{c}\text { Direct effect } \\
\text { (With mediator) }\end{array}$ & $\begin{array}{l}\text { Indirect effect } \\
\text { (With mediator) }\end{array}$ \\
\hline \multicolumn{5}{|c|}{ Model 1: resource measures $(n=87)$} \\
\hline Target rigidity & Team adaptability & Project success & $0.19(1.73)^{*}$ & $0.09(1.50)$ \\
\hline Process autonomy & Team adaptability & Project success & $-0.05(0.40)$ & $0.11(1.87)^{*}$ \\
\hline \multicolumn{5}{|c|}{ Model 2: cost measures $(n=86)$} \\
\hline Target rigidity & Team adaptability & Project success & $0.22(2.24)^{* * *}$ & $0.13(1.99)^{*}$ \\
\hline Process autonomy & Team adaptability & Project success & $-0.10(1.09)$ & $0.12(1.97)^{*}$ \\
\hline \multicolumn{5}{|c|}{ Notes: $* p<0.10 ; * * p<0.05$ (two-tailed) } \\
\hline
\end{tabular}


Robustness check

We test whether unpredictability due to internal influences (i.e. related to target technologies, target production processes and target customer requirements) and external influences (i.e. related to competitors' and suppliers' behaviours and legal developments) affects the hypothesised relationships. We conduct a moderator analysis in which we separately test the influence of unpredictability for our two models (resource and cost models). Our results indicate that neither internal nor external influences significantly affect the examined relationships, suggesting that our models hold independent of internal and external unpredictability.

\section{Discussion and conclusion}

Discussion

We explore the direct and indirect effects of two formal controls, target rigidity and process autonomy, on team adaptability and project success in NPD projects. Specifically, we hypothesise that target rigidity (output control) and process autonomy (behaviour control) provide NPD teams with both the motivation (target rigidity) and discretion (process autonomy) to adapt to new developments, which subsequently affects NPD project success. We distinguish between two types of measures (resource and cost measures) to enhance our knowledge on how formal controls affect NPD project success by identifying antecedents and consequences of team adaptability in NPD projects.

Our results indicate that formal controls have the potential to increase NPD project effectiveness (e.g. Rijsdijk and Van den Ende, 2011; Davila, 2000). The simultaneous use of target rigidity and process autonomy extends previous studies that have highlighted the relevance of control combinations in innovative settings (e.g. Cardinal, 2001; Rijsdijk and Van den Ende, 2011) and emphasised the need for autonomy within project structures (e.g. Bonner et al., 2002). Our results suggest that companies can improve NPD performance by adequately choosing control configurations, that is, by defining project targets and decentralising process autonomy to the project team. This appears to provide a motivating environment that enhances NPD success. Rather surprising is that these controls appear to be relatively independent. Our correlation analyses suggest that companies make these decisions independently; additional case study research may investigate if, and how companies make these decisions on the (joint) use of controls in NPD settings.

Our study also opens the "black box" of the relationship between formal controls and project success by highlighting the mediating role of team adaptability. We extend previous theoretical contributions (e.g. Burke et al., 2006) and developing empirical research in other team environments (e.g. consulting, Klarner et al., 2013) that has pointed out the importance of team adaptability in uncertain environments with non-routine tasks. Our results confirm previous research (e.g. Thongpapanl et al., 2012; Klarner et al., 2013) that structural arrangements (in our case the design of formal controls) are important antecedents of team adaptability. Our results show that target rigidity and process autonomy have positive associations with team adaptability, which - in turn - has a strong positive effect on project success. These results suggest that rigid targets facilitate team adaptability and team effort, since they help to identify

\begin{tabular}{llllc}
\hline Path from & Path to & $H$ & $\beta_{(1)}-\beta_{(2)}$ & $t$-statistics \\
\hline Target rigidity & Adaptability & $H 2 a$ & 0.060 & $(0.36)$ \\
& Project success & $\mathrm{NP}$ & 0.028 & $(0.18)$ \\
Process autonomy & Adaptability & $H 2 b$ & 0.003 & $(0.02)$ \\
& Project success & $\mathrm{NP}$ & 0.059 & $(0.39)$ \\
Team adaptability & Project success & $H 1$ & 0.060 & $(0.43)$
\end{tabular}

Notes: $H$, hypothesis; NP, not predicted
Formal controls and team adaptability

1551 
deviations in operational activities during project execution and provide incentives to change activities. It also suggests that process autonomy provides NPD teams the opportunity to alter operations in order to increase project success. Our empirical results also imply that target rigidity has a somewhat superior role relative to process autonomy concerning project success, indicating that flexibility needs to be structured to provide reference points.

Finally, we did not find support for our hypothesis that different types of measures (resource vs cost measures) have different consequences for NPD success. One potential explanation is that the difference between resource and cost measures may not be substantial enough: for example, the consumption of materials, use of equipment and number of working hours eventually translate into costs. In addition, competitive strategy may affect the salience of specific performance measures for NPD projects (see Davila, 2000).

\section{Managerial implications}

Our findings provide important insights for (NPD project) managers. First, our results suggest that firms can increase project success by using formal controls in such a way that they allow project managers to provide their teams with motivating guidelines (target rigidity) and discretion (process autonomy) to adapt to new circumstances. This way, performance measures are means that enable project managers to supervise the NPD team's work and attain specific project targets rather than coercive mechanisms that limit innovation. Second, managers should be aware that implementing one control mechanism (e.g. introduction of behaviour controls that limit the freedom of project teams) may impact the effectiveness of other control mechanisms (e.g. target rigidity), as teams cannot adapt their operations effectively to new information. Our results suggest that organisations make decisions on behaviour and output controls rather independently (i.e. process autonomy and target rigidity are not correlated). However, managers should be aware of these trade-offs when trying to generate working conditions that facilitate project execution.

\section{Limitations and future research directions}

This study has some limitations that could be addressed in future research. First, our study focusses on the project managers' perspective; subsequent research may evaluate NPD performance from top management or team member perspectives in order to investigate whether perceptions of target rigidity and process autonomy vary across different hierarchical levels. Furthermore, additional research may also investigate the effectiveness of other control elements and control configurations in NPD settings. Second, all limitations concerning survey research apply; these include reflection on perceptions of NPD project managers rather than on hard numbers, lack of insight concerning survey responses, and potentially omitted variable bias. To address these limitations, future research might not focus on one hierarchical level (i.e. project managers) but ask for the chief innovation officers' perception additionally in order to assess whether the project managers' use of performance measures is in line with the standards defined at higher hierarchical levels. This would also be in favour of a more objective assessment of the project success, given that the chief innovation officers receive detailed information (e.g. on timeliness and budget adherence) for the individual projects. A potential downside is that project managers may strategically report on selected projects once they are aware that higher managers will also evaluate their projects. Furthermore, subsequent research may use other research methods (e.g. archival or case studies) as a means to get insights into potentially distinct perceptions of different hierarchical levels. Third, we focus on a specific use of a performance measurement system (communication of goals through targets) rather than other uses of performance measures (rewarding, strategic learning, accountability, etc.). In this project, we have focussed on two types of measures that are considered important in most NPD projects (cost and resource allocation). Additional 
research may also investigate the impact of other types of performance measures that are used in NPD settings (e.g. response time, customer, time to market; Davila, 2000; Henttonen et al., 2016). In addition, subsequent research may focus on the performance measure characteristics (e.g. completeness, controllability, timeliness, etc.; see Merchant, 2006). The use of performance measures and definition of targets is also related to the question of how to define appropriate goals (see, e.g. Latham and Locke, 2006) to ensure that they do not lead to deceitful behaviour (Den Nieuwenboer et al., 2017). Further research is necessary to get a better understanding on how rigid targets can be determined in a setting with inherent uncertainty, such as NPD projects. If top managers force unrealistically high targets on the project managers, team adaptability might be substituted with deceitful behaviour. Rather than working to achieve the targets, NPD teams may deceive others within the organisation into believing that performance targets are being met when they are not. Furthermore, we have considered only one factor (i.e. unpredictability) that may affect the use of performance measures in NPD project; additional research may investigate other factors that may moderate the above mentioned relations (see, e.g. Sicotte and Bourgault, 2008). Finally, extending our study to other industries (e.g. pharmaceutical or biotech firms) and other countries (with specific institutional characteristics different from Germany) may provide additional insights.

To conclude, this study reveals the impact of formal controls on NPD project success through team adaptability. A better understanding of the role of these formal controls and their impact on team adaptability may help in improving NPD project success; future research may build upon this study to further investigate how formal controls can be used effectively in NPD projects.

\section{Notes}

1. A parametric test for multi group analysis assumes a normal distribution of the data. We used IBM SPSS Statistics (Version 23) to test the data beforehand.

2. In a first step, we test the paths' variances (standard errors) for significant differences across the groups of resource and cost measures (Levene's test for equality of variances). As we did not find indication that the paths' variances differ significantly, we compute the test statistics for equal standard errors (se):

$$
t=\frac{\beta_{(1)}-\beta_{(2)}}{\sqrt{\frac{\left(n_{(1)}-1\right)^{2}}{n_{(1)}+n_{(2)}-2} \cdot \mathrm{se}_{\beta_{(1)}}^{2}+\frac{\left(n_{(2)}-1\right)^{2}}{n_{(1)}+n_{(2)}-2} \cdot \mathrm{se}_{\beta_{(2)}}^{2}+\sqrt{\frac{1}{n_{(1)}}+\frac{1}{n_{(2)}}}}}
$$

\section{References}

Amabile, T.M. (1998), "How to kill creativity", Harvard Business Review, September-October, pp. 77-87.

Atkinson, R. (1999), "Project management: cost, time and quality, two best guesses and a phenomenon, its time to accept other success criteria", International Journal of Project Management, Vol. 17 No. 6, pp. 337-342.

Bedford, D.S. (2015), "Management control systems across different modes of innovation: implications for firm performance", Management Accounting Research, Vol. 28, Special Issue, pp. 12-30.

Blindenbach-Driessen, F., Van Dalen, J. and Van den Ende, J. (2010), "Subjective performance assessment of innovation projects", Journal of Product Innovation Management, Vol. 27 No. 4, pp. 572-592.

Bonner, J.M., Ruekert, R.W. and Walker, O.C. (2002), "Upper management control of new product development projects and project performance", Journal of Product Innovation Management, Vol. 19 No. 3, pp. 233-245. 
$\mathrm{MD}$

56,7

Brown, S.L. and Eisenhardt, K.M. (1995), "Product development: past research, present findings, and future directions", Academy of Management Review, Vol. 20 No. 2, pp. 343-378.

Burke, C.S., Stagl, K.C., Salas, E., Pierce, L. and Kendall, D. (2006), "Understanding team adaptation: a conceptual analysis and model", Journal of Applied Psychology, Vol. 91 No. 6, pp. 1189-1207.

Cardinal, L.B. (2001), "Technological innovation in the pharmaceutical industry: the use of organizational control in managing research and development”, Organization Science, Vol. 12 No. 1, pp. 19-36.

Chang, L., Cheng, M. and Trotman, K.T. (2008), "The effect of framing and negotiation partner's objective on judgments about negotiated transfer prices", Accounting, Organizations and Society, Vol. 33 No. 7, pp. 704-717.

Chiesa, V. and Masella, C. (1996), "Searching for an effective measure of R\&D performance", Management Decision, Vol. 34 No. 7, pp. 49-57.

Chiesa, V., Frattini, F., Lazzarotti, V. and Manzini, R. (2009), "An exploratory study on R\&D performance measurement practices: a survey of Italian R\&D-intensive firms", International Journal of Innovation Management, Vol. 13 No. 1, pp. 65-104.

Chin, W.W. (2010), "How to write up and report PLS analyses", in Esposito Vinzi, V., Chin, W.W., Henseler, J. and Wang, H. (Eds), Handbook of Partial Least Squares - Concepts, Methods and Applications, Springer, Heidelberg, pp. 655-690.

Chong, K.M. and Mahama, H. (2014), "The impact of interactive and diagnostic uses of budgets on team effectiveness", Management Accounting Research, Vol. 25 No. 3, pp. 206-222.

Cooper, L.P. (2003), "A research agenda to reduce risk in new product development through knowledge management: a practitioner perspective", Journal of Engineering and Technology Management, Vol. 20 No. 1, pp. 117-140.

Cordero, R. (1990), "The measurement of innovation performance in the firm: an overview", Research Policy, Vol. 19 No. 2, pp. 185-192.

Damanpour, F. (1991), "Organizational innovation: a meta-analysis of effects of determinants and moderators", Academy of Management Journal, Vol. 34 No. 3, pp. 555-590.

Davila, T. (2000), "An empirical study on the drivers of management control systems' design in new product development", Accounting, Organizations and Society, Vol. 25 Nos 4-5, pp. 383-409.

Davila, T. (2005), "An exploratory study on the emergence of management control systems: formalizing human resources in small growing firms", Accounting, Organizations and Society, Vol. 30 No. 3, pp. 223-248.

Den Nieuwenboer, N.A., Cunha, J.V.D. and Treviño, L.K. (2017), "Middle managers and corruptive routine translation: the social production of deceptive performance", Organization Science, Vol. 28 No. 5, pp. 781-803.

Dvir, D. and Lechler, T. (2004), "Plans are nothing, changing plans is everything: the impact of changes on project success", Research Policy, Vol. 33 No. 1, pp. 1-15.

Dvir, D., Sadeh, A. and Malach-Pines, A. (2006), "Projects and project managers: the relationship between project managers' personality, project types and project success”, Project Management Journal, Vol. 37 No. 5, pp. 36-48.

Esposito Vinzi, V., Trinchera, L. and Amato, S. (2010), "PLS path modeling: from foundations to recent developments and open issues for model assessment and improvement", in Esposito Vinzi, V., Chin, W.W., Henseler, J. and Wang, H. (Eds), Handbook of Partial Least Squares - Concepts, Methods and Applications, Springer, Heidelberg, pp. 47-82.

Götz, O., Liehr-Gobbers, K. and Krafft, M. (2010), "Evaluation of structural equation models using partial least squares (PLS) approach", in Esposito Vinzi, V., Chin, W.W., Henseler, J. and Wang, H. (Eds), Handbook of Partial Least Squares - Concepts, Methods and Applications, Springer, Heidelberg, pp. 691-711. 
Hair, J.F., Ringle, C.M. and Sarstedt, M. (2011), "PLS-SEM: indeed a silver bullet”, Journal of Marketing Theory and Practice, Vol. 19 No. 2, pp. 139-151.

Hair, J.F., Hult, G.T.M., Ringle, C.M. and Sarstedt, M. (2014), A Primer on Partial Least Squares Structural Equation Modelling (PLS-SEM), Sage, Los Angeles, CA.

Henri, J.F. (2006), "Organizational culture and performance measurement systems", Accounting, Organizations and Society, Vol. 31 No. 1, pp. 77-102.

Henseler, J., Ringle, C.M. and Sinkovics, R.R. (2009), "The use of partial least squares path modeling in international marketing”, Advances in International Marketing, Vol. 20 No. 1, pp. 277-319.

Henttonen, K., Ojanen, V. and Puumalainen, K. (2016), "Searching for appropriate performance measures for innovation and development projects”, R\&D Management, Vol. 46 No. 5, pp. 914-927.

Hirst, G. and Mann, L. (2004), "A model of R\&D leadership and team communication: the relationship with project performance”, R\&D Management, Vol. 34 No. 2, pp. 147-160.

Hu, J. and Liden, R.C. (2011), "Antecedents of team potency and team effectiveness: an examination of goal and process clarity and servant leadership", Journal of Applied Psychology, Vol. 96 No. 4, pp. 851-862.

Hulland, J. (1999), "Use of partial least squares (PLS) in strategic management research: a review of four recent studies", Strategic Management Journal, Vol. 20 No. 2, pp. 195-204.

Jarvis, C.B., Mackenzie, S.B. and Podsakoff, P.M. (2003), "A critical review of construct indicators and measurement model misspecification in marketing and consumer research", Journal of Consumer Research, Vol. 30 No. 2, pp. 199-218.

Jørgensen, B. and Messner, M. (2009), "Management control in new product development: the dynamics of managing flexibility and efficiency", Journal of Management Accounting Research, Vol. 21 No. 1, pp. 99-124.

Klarner, P., Sarstedt, M., Hoeck, M. and Ringle, C.M. (2013), "Disentangling the effects of team competences, team adaptability, and client communication on the performance of management consulting teams", Long Range Planning, Vol. 46 No. 3, pp. 258-286.

Latham, G.P. and Locke, E.A. (2006), "Enhancing the benefits and overcoming the pitfalls of goal setting”, Organizational Dynamics, Vol. 35 No. 4, pp. 332-340.

LePine, J.A. (2003), "Team adaptation and postchange performance: effects of team composition in terms of members' cognitive ability and personality”, Journal of Applied Psychology, Vol. 88 No. 1, pp. 27-39.

LePine, J.A. (2005), "Adaptation of teams in response to unforeseen change: effects of goal difficulty and team composition in terms of cognitive ability and goal orientation", Journal of Applied Psychology, Vol. 90 No. 6, pp. 1153-1167.

MacBryde, J. and Mendibil, K. (2003), "Designing performance measurement systems for teams: theory and practice", Management Decision, Vol. 41 No. 8, pp. 722-733.

March, J.G. and Shapira, Z. (1987), "Managerial perspectives on risk and risk taking", Management Science, Vol. 33 No. 11, pp. 1404-1418.

Marks, M.A., Mathieu, J.E. and Zaccaro, S.J. (2001), “A temporally based framework and taxonomy of team processes", Academy of Management Review, Vol. 26 No. 3, pp. 356-376.

Merchant, K.A. (2006), "Measuring general managers' performances: market, accounting and combinationof-measures systems”, Accounting, Auditing \& Accountability Journal, Vol. 19 No. 6, pp. 893-917.

Mundy, J. (2010), "Creating dynamic tensions through a balanced use of management control systems", Accounting, Organizations and Society, Vol. 35 No. 5, pp. 499-523.

Preacher, K.J. and Hayes, A.F. (2004), "SPSS and SAS procedures for estimating indirect effects in simple mediation models", Behavior Research Methods, Instruments, \& Computers, Vol. 36 No. 4, pp. 717-731.

Pulakos, E.D., Arad, S., Donovan, M.A. and Plamondon, K.E. (2000), "Adaptability in the workplace: development of a taxonomy of adaptive performance", Journal of Applied Psychology, Vol. 85 No. 4, pp. 612-624. 
Rauniar, R., Doll, W., Rawski, G. and Hong, P. (2008), "The role of heavyweight product manager in new product development", International Journal of Operations \& Production Management, Vol. 28 No. 2, pp. 130-154.

Rijsdijk, S.A. and Van den Ende, J. (2011), "Control combinations in new product development projects", Journal of Product Innovation Management, Vol. 28 No. 6, pp. 1-13.

Ringle, C.M., Wende, S. and Will, A. (2005), "SmartPLS 2.0.M3", SmartPLS, Hamburg, available at: www.smartpls.de

Ringle, C.M., Boysen, N., Wende, S. and Will, A. (2006), "Messung von Kausalmodellen mit dem PartialLeast-Squares-Verfahren”, Wirtschaft und Studium, Vol. 35 No. 1, pp. 81-87.

Salomo, S., Weise, J. and Gemünden, H.G. (2007), "NPD planning activities and innovation performance: the mediating role of process management and the moderating effect of product innovativeness", Journal of Product Innovation Management, Vol. 24 No. 4, pp. 285-302.

Schrader, S. and Göpfert, J.R. (1998), "Zielklarheit und Zieloffenheit. Eine empirische Analyse der Zusammenarbeit von Herstellern und Zulieferern in der Produktentwicklung", in Franke, N. and v. Braun, C.-F. (Eds), Innovationsforschung und Technologiemanagement-Konzepte, Strategien, Fallbeispiele, Springer, Heidelberg, pp. 191-204.

Sethi, R. and Iqbal, Z. (2008), "Stage-gate controls, learning failure, and adverse effect on novel new products", Journal of Marketing, Vol. 72 No. 1, pp. 118-134.

Sicotte, H. and Bourgault, M. (2008), "Dimensions of uncertainty and their moderating effect on new product development project performance", R\&D Management, Vol. 38 No. 5, pp. $468-479$.

Simons, R. (1990), "The role of management control systems in creating competitive advantage: new perspectives”, Accounting, Organizations and Society, Vol. 15 Nos 1/2, pp. 127-143.

Snell, S.A. (1992), "Control theory in strategic human resource management: the mediating effect of administrative information", Academy of Management Journal, Vol. 35 No. 2, pp. 292-327.

Sundstrom, E., De Meuse, K.P. and Futrell, D. (1990), "Work teams: applications and effectiveness", American Psychologist, Vol. 45 No. 2, pp. 120-133.

Tatikonda, M.V. and Montoya-Weiss, M.M. (2001), "Integrating operations and marketing perspectives of product innovation: the influence of organizational process factors and capabilities on development performance", Management Science, Vol. 47 No. 1, pp. 151-172.

Tatikonda, M.V. and Rosenthal, S.R. (2000), "Successful execution of product development projects: balancing firmness and flexibility in the innovation process", Journal of Operations Management, Vol. 18 No. 4, pp. 401-425.

Thamhain, H.J. (2003), "Managing innovative R\&D teams", R\&D Management, Vol. 33 No. 3, pp. 297-311.

Thongpapanl, N.T., De Clercq, D. and Dimov, D. (2012), "An investigation of the performance consequences of alignment and adaptability: contingency effects of decision autonomy and shared responsibility", R\&D Management, Vol. 42 No. 1, pp. 14-30.

Turner, K.L. and Makhija, M.V. (2006), "The role of organizational controls in managing knowledge", Academy of Management Review, Vol. 31 No. 1, pp. 197-217.

Van der Stede, W.A. (2000), "The relationship between two consequences of budgetary controls: budgetary slack creation and managerial short-term orientation", Accounting, Organizations and Society, Vol. 25 No. 6, pp. 609-622.

Zhu, Y.Q. and Chen, H.G. (2016), "Empowering leadership in R\&D teams: a closer look at its components, process, and outcomes", R\&D Management, Vol. 46 No. 4, pp. 726-735. 
Appendix 1: Indicators

Target rigidity (TargRig)

The level of agreement with the following statements $(1=$ Not true at all, $5=$ Completely true); these statements were evaluated separately with regard to resource and cost measures.

TargRig1 After the determination of the important project parameters, they were fixed and there was no leeway for negotiations

TargRig2 After an accepted review, the goal parameters had to be realised

TargRig3 The original goal definition was a fixed standard according to which the project's progress was measured
Formal

controls and

team

adaptability

1557

Table AI.

Target rigidity

(TargRig)

\section{Process autonomy (ProcAut)}

The level of agreement with the following statements $(1=$ Not true at all, $5=$ Completely true); these statements were evaluated separately with regard to resource and cost measures.

ProcAut1 My project team was free to choose and organise the ways and means for goal attainment. (For instance, high degree of freedom regarding the applied technology.)

ProcAut2 Within the project's progress, my project team was free to determine a convenient time for attaining certain activities. (For instance, low degree of freedom regarding weekly tasks; high degree of freedom regarding annual tasks.)

ProcAut3 Within goal attainment, my project team was free to organise and determine the extent of certain activities. (For instance, the allocation of the total budget to individual tasks.)

Table AII.

Process autonomy (ProcAut)

\section{Team adaptability (Adapt)}

The level of agreement with the statements $(1=\mathrm{I}$ completely disagree, $5=\mathrm{I}$ completely agree).

Adapt1 We were able to identify specific areas that were affected by changes early on

Adapt2 We were able to develop change plans at an early stage in order to manage emerging changes

Adapt3 We were able to initiate arrangements for specific areas in order to manage changes with little effort at an early stage

Adapt4 If activities within the development process did not lead to the intended results, changes could be implemented soon and with little effort

Adapt5 We were able to react early and with little effort to changed conditions and unforeseen events

Table AIII.

Team adaptability

(Adapt)

\section{Project Success (ProjSuc)}

The project success level $(1=$ very strongly undershot, $7=$ very clearly outperformed $)$.

ProjSucl

ProjSuc2

ProjSuc3

ProjSuc4

ProjSuc5
Achievement of profit goals

Achievement of rentability goals (e.g. ROI or IRR)

Adherence of the predetermined production costs

Adherence of the schedule

Adherence of the predetermined time to market
Table AIV.

Project Success

(ProjSuc) 


\section{Control variables}

\section{8}

Table AV.

Control variables

Tenure Ten1 How long have you been working for the company?

Ten2 How long have you been working in this function?

Industry Indust Indication of the specific industry

Size Size How many employees were working on your project, measured in terms of full-time workers?

\section{Unpredictability}

Please estimate the unpredictability level according to the following aspects $(1=$ very low, $5=$ very high); since in the survey, we asked for predictability, we renamed and recoded the construct.

Table AVI.

Unpredictability
Internal factors

External factors

\section{Corresponding author}

Nina Detzen can be contacted at: n.detzen@vu.nl

For instructions on how to order reprints of this article, please visit our website:

Target product technology

Target production process

Target customer requirements

Competitors' behaviour

Suppliers' behaviour

Legal and political developments 